University of Colombo Review (Series III),

Vol. 2, No. 1, 2021

\title{
Universal Assessment: Reflections on Equitable Evaluations in a Sri Lankan Higher Education Classroom
}

\section{Shalini A. Abayasekara}

Probationary Lecturer, Department of English, University of Colombo

ABSTRACT
This article considers issues of equity in tertiary level assessment in
the context of students with disabilities (SWDs). Using the concept
of universal design for learning (UDL), it highlights two approaches
educators can take - a) formulating a uniform assessment for all
students including those with disabilities, or b) designing alternative
assessments for SWDs. The article also examines existing models
and definitions of disability, their interplay with assessment within the
framework of UDL, and conditions for SWDs in the Sri Lankan higher
education environment. It takes a specific instance where assessment
was adjusted to suit the needs of an undergraduate student with a
hearing impairment (HI) and analyzes it as a case study, combining
aspects of autoethnography to obtain an in-depth view of the student's
perspectives on the changed assessment, my own evaluation practice,
and assessment practices in general. Building on my own reflections
through a semi-structured interview, key ways in which the student
approaches learning, and particularly assessment, are outlined. They
include a consideration of how given tasks relate to the entire class,
the time needed for completion, sensitivity to individual strengths
and group dynamics, general awareness regarding deafness, and
assessment type. Student consultation in assessment design and
educator cognizance and training also surface as important factors, all
of which together could contribute towards the navigation of disability
in respectful and productive ways.

KEY WORDS:

Students with disabilities, assessment, UDL, case study, autoethnography, disability awareness

Suggested Citation: Abayasekara, S. A. (2021). Universal assessment: Reflections on equitable evaluations in a Sri Lankan higher education classroom. University of Colombo Review (New Series III), 2(1), 102 - 118.

(C) 2021 The Authors. This work is licenced under a Creative Commons Attribution 4.0 International Licence which permits unrestricted use, distribution, and reproduction in any medium, provided the original work is properly cited. 


\section{Assessment and Disability}

One in five people experience some form of disability (The World Bank, 2021). Despite this high rate of prevalence, disability is rarely openly discussed in the higher education classroom. It is also rarely considered in curriculum design.

Assessment plays an integral role in curriculum design. As noted in Abayasekara (2020), and Gibbs and Habeshaw (1989/2011), assessment is the most powerful instrument an educator has with regard to student learning. Biggs and Tang (2007) comment that "what and how students learn depends to a major extent on how they think they will be assessed" (p. 163). Within the general purpose of using assessment to enhance student learning, Brown and Smith (1997) list several sub-purposes of assessment, such as providing constructive feedback to students, classifying student achievement, and aiding students to apply theoretical principles to practical contexts.

\section{Definitions and Models of Disability}

Considering the role assessment plays in student learning, a vital question becomes assessment design for students with disability. The United Nations Convention on the Rights of Persons with Disabilities (UNCRPD, 2006) describes disability as "result[ing] from the interaction between persons with impairments and attitudinal and environmental barriers that hinders their full and effective participation in society on an equal basis with others" ( $p$. 1). Mendis and Perera (2019) also highlight that disability encompasses a consideration of a person's body, such as eyes, ears, and mind, and how it intersects with the daily functions and social roles the person carries out. An individual can, thereby, be made disabled because of obstacles in the environment, which could include both social attitudes and inaccessible physical spaces (Abayasekara, 2020).

This view of disability closely aligns with the social model of disability. Berghs et al. (2019) state that the social model of disability has developed "from the experiences of disabled people and their activism against the charity and medical models of disability, as well as the control that these professionals exerted over their lives" (p. 6). The charity model views disability as something to be pitied and in need of charitable assistance while the medical model sees disability as a problem or anomaly that needs to be cured (Berghs et al., 2019). These models come under what Oliver (1990) terms the "individual model of disability", as they "locate the 'problem' of disability within the individual and...see the causes of this problem as stemming from the functional limitations or psychological losses which are assumed to arise from disability" (as cited in Lawson \& Beckett, 2020, p. 349). In contrast, Johnson (2011) argues that, according to the social model of disability, impairment is in fact a common experience for humans, and it is not impairment itself but societal practices that disable an individual. The model also makes a distinction between "impairment" as a functional limitation, and "disability" as the result of the interaction between people with impairments and their social, cultural, and physical environments (Johnson, 2011).

The human rights-based model, with its focus on the inherent dignity of the human being and the individual's right to choice and control of all decisions affecting him/her, 
likewise locates the main problem in societal factors external to the person with disabilities (Lawson \& Beckett, 2020). Clearly then, the social and rights-based approaches to disability and the definition of disability highlighted by the UNCRPD (2006) and by Mendis and Perera (2019) are linked. Accordingly, a person may experience difficulties engaging in day-to-day activities due to his/her state of health combined with the barriers created by society. My own definition of disability is similar: a combination of an impairment (physical, psychosocial, or intellectual) and obstacles in the physical and/or social environment that prevent the individual from performing general tasks to his/her maximum capacity in a particular context. Such a definition allows me to consider what aspects of the environment can be improved in order to optimally support the pedagogical process of students with disabilities (SWDs).

\section{Designing Assessment}

In light of the above definitions and models of disability, several factors need to be taken into account when designing assessments. As observed by Abayasekara (2020), educators should not deploy a charity or medical perspective towards SWDs as helpless individuals who cannot successfully implement given tasks. One also needs, however, to acknowledge disability in the classroom and not treat it as something "invisible" or "illegitimate" (Bessant, 2012). While acknowledging its presence, the educator must also go the further step of maximizing the potential the environment offers, in order to ensure that the active participation of SWDs is not hindered because of any preventable external factor (Abayasekara, 2020). Hanafin et al. (2007) emphasize the necessity to do so, observing that "the taken-for-granted nature of the assessment modus operandi readily conceals discrimination and makes it easy to explain achievement (and underachievement) in terms of individual deficit rather than unjust and partial institution practices" (p. 443).

As noted in Abayasekara (2020), environmental factors in assessment cover components such as assessment type, duration given for preparation and/or implementation, accessible formats, and, in the case of a group project, fellow group members. Considering that one purpose of assessment, as described by Brown and Smith (1997), is to classify student achievement, educators need to consider how assessments can be conducted in a manner that evaluates all students justly and equitably (Abayasekara, 2020), thereby providing a fair chance for achievement and an accurate measurement of achievement. If not, "students could feel disregarded, demotivated and even incompetent" (Abayasekara, 2020 , p. 8). Hanafin et al. (2007) also note how "[t]he modes and techniques used to assess probably have the most immediate influence on how a learner will experience an assessment practice, and they significantly influence how inclusive an assessment practice is felt to be" (p. 438).

\section{Universal Design and Universal Design for Learning}

The utilization of the environment comes under the principles of universal design (UD). Citing Ronald Mace, one of the originators of the principle of UD, Dolmage (2017) writes that "universal design is the design of products and environments to be usable by 
all people, to the greatest extent possible, without the need for adaptation or specialized design" (p. 115). He goes on to note that the concept of universal design for learning (UDL) has become a philosophy of teaching adapted from this architectural base-advocating the use of multiple and flexible strategies to address the needs of all students. According to the three major tenets of UDL, there needs to be a) varied means of student engagement, b) varied methods of delivering content, and c) varied ways for students to express themselves and act (Dolmage, 2017).

Within UDL, multiple strategies exist in order to make assessment more "userfriendly" for SWDs. One is the notion of equitable assessment arrangement (EAA), also known as alternative assessment or reasonable adjustment (Bessant, 2012). EAA is described as "an adjustment or alteration to the standard conditions or format of assessment... [where] students...still meet the inherent requirements of the course and program" (Royal Melbourne Institute of Technology (RMIT) University, n.d.). Here, SWDs may receive a different assessment to their peers in terms of conditions and/or format, based on the principle of equity. Another way of making assessments accommodating, is to design an assessment suitable to the entire class rather than adjusting it for SWDs only. This practice abides by the principles of UD that promotes accessibility for all. In such a context, the educator would need to ensure that the type and manner of assessment are equally accessible to everyone, regardless of the student's dis/ability.

\section{Higher Education in Sri Lanka: Disability-Related Policies and Practices}

Discussing policies related to persons with disability in Sri Lanka as a whole, Peiris-John et al. (2013) observe that legal and policy development in this area is still in its preliminary stages and that the State's responsibility towards persons with disabilities is unsatisfactory. The primary legislation regarding the rights of persons with disabilities in Sri Lanka is the Protection of the Rights of Persons with Disabilities (PRPD) Act of 1996, which does not meet the standards of the UNCRPD (Jiffry \& Perera, 2017, as cited in Perera et al., 2020). While Perera et al. (2020) note that the National Policy on Disability (NPD) of 2003 and the National Action Plan for Disability (NAPD) of 2013 provide frameworks and mechanisms for ensuring the rights of persons with disabilities, and that the National Human Rights Action Plans of 2011-2015 and 2016-2020 also mention the rights of those with disabilities, Samararatne and Soldatic (2015) observe that none of these measures have been implemented effectively.

Specifically looking at education within this policy framework, Hettiarachchi et al. (2016) state that while the Fundamental Rights Chapter of the Constitution of Sri Lanka does not specify a right to education, the Directive Principles of State policy acknowledges the State's duty to eliminate illiteracy and ensure universal and equal access to education. They note that the PRPD, in its Article 23(1), states that "no person with a disability shall be discriminated against, on the ground of such disability to any Educational Institution" (p. 3), and that Article 13 (1) and (m) makes provision for the education of persons with disabilities as a function of the National Council on Disability. Hettiarachchi et al. further note that while the NPD had set out strategies for promoting and protecting the educational 
rights of children living with disabilities, education was a thematic area listed in the NAPD which was in force until 2017 (L. Daskon-Attanayake, personal communication, March 30, 2021).

However, the situation with regard to the rights of persons with disabilities in higher education reinforces Peiris-John et al.'s (2013) observations on the unsatisfactory nature of policy implementation. The NPD highlights that very few individuals with disabilities have had higher education. In their study sample, only one percent of those with visual impairment and three percent of those with speech impairment had attended university. As Hettiarachchi et al. (2016) observe, the number of students enrolled in tertiary education in Sri Lanka is lower than other countries of similar economic standing. Yatigammana et al. (2021) point out that the total number of SWDs admitted to state/national universities from among those who satisfy the minimum requirements under the "special intake" category is even smaller, compared to overall enrollment.

Moreover, SWDs are limited by the choice of courses available to them. The NPD (Ministry of Social Welfare, 2003) draws attention to this issue, and almost two decades later, Yatigammana et al., (2021) make the same observation that SWDs are limited to taking courses in the Social Sciences and Humanities. In the latter's study sample of 32 SWDs from four state/national universities, only about $65 \%$ had registered for a degree program of their choice.

Following enrollment too, SWDs face numerous obstacles. Examining the situation at two state universities, Hettiarachchi et al. (2016) highlight issues of accessibility because of infrastructure. Some of their respondents described the challenges of rough roads for students who use wheelchairs, the lack of a functioning elevator, and cows on the main road that pose a significant danger to students with visual impairment. A student noted a waiver on the $80 \%$ attendance requirement for a course, because she was unable to walk and classes were held on the second floor. As Hettiarachchi et al. further argue, while the student was deprived of her right to attend classes, the "solution" of being excused failed to address underlying inequities. They also describe a sense of resignation experienced by SWDs, who seem to accept inaccessibility as their lot, and do not expect or fight for anything better. Difficulties in following lectures because of their pace, ambient noise, and poor-quality acoustics in lecture halls were also noted. Again, while students appreciated some lecturers' attempts to go through the lesson material at a slower pace, they demonstrated resignation in not expecting all staff to do the same. The SWDs also indicated disappointment at being perceived by some lecturers as those who have limited ability, which led to them being excluded from class discussion.

Yatigammana et al. (2021) point to the same, or similar difficulties, faced by SWDs in their study sample from four Sri Lankan universities, such as inability to access facilities, lack of information and appropriate reading material and lack of adequate accommodation. They note that due to these obstacles, SWDs received low grades, limited opportunities to participate in internships, poor interaction with fellow students and fewer job opportunities. They also faced discrimination by peers who did not identify as having a disability and confronted attitudinal barriers when attempting to join extracurricular activities. It is 
possible that these barriers were also partly due to the fact that only three percent of their sample of university academics had been trained in teaching SWDs.

However, universities have also made progress in improving the learning experience for SWDs. Yatigammana et al. (2021) state that two universities in their survey provide preferential seating, extra handouts, copies of course notes and course requirements in advance, computers or recording devices for notetaking, notetaking friends, tutoring, and in the case of one university, peer support. At another state university, SWDs are provided guidance in the registration process by the support center for SWDs which operates under a larger center of the university dedicated to disability research and practice. Following registration, this center notifies lecturers of the SWDs in their classes. Disability officers are appointed from each department to coordinate with this larger center as well as their respective departments, to ensure that the pedagogical needs of SWDs are communicated and discussed with the lecturers. While this process began in 2020 and is, therefore, still at its initial stages of implementation, it constitutes a clear move towards making education more inclusive. The same university has also taken another major step in offering a course on disability awareness and sensitization to its academic and non-academic staff at its Faculty of Arts.

Assessment practices have also been modified to accommodate student needs, though there is much room for further improvement. All SWDs in Yatigammana et al.'s (2021) survey reported being given extra time for examinations. In Hettiarachchi et al.'s (2016) study, a student highlighted positive changes in the institution's effort to make recording devices such as braille machines more accessible at examinations. Students at a different state university reported that they also receive other forms of support at exams when necessary, such as a scribe or an invigilator who reads out the examination paper, although in some courses students now receive the paper in braille. Some of these measures, however, are inadequate. For instance, there is lack of uniformity between one invigilator-reader and another and the resultant differences can affect student performance. Inability to judge a student's spelling can also occur when the answer is recorded by an invigilator. Additionally, Hettiarachchi et al. (2016) stated that one of their respondents reported insufficient space to keep all her exam-related material with her and not having had an assistant during an examination. Yatigammana et al. (2021) further observed that only one percent of the academics in their study felt SWDs needed a separate place for examinations. While mid-semester evaluations are generally the responsibility of the individual lecturer, here too, necessary accommodations should be uniformly made as a matter of policy and practice such as willingness to give SWDs extra time to complete assignments (Yatigammana et al. (2021).

\section{Implementing Change}

I now turn to a specific instance where I had to make choices regarding continuous assessments. As I have discussed this process in depth elsewhere (Abayasekara, 2020), I provide a summary here. One course I teach, Rhetoric and Style, has three assessments focusing on various angles of rhetoric. The first tests general skills of rhetorical analysis by 
requiring students to select a text (written or audiovisual) and analyze its rhetorical features (or lack thereof), as well as comment on a peer's analysis. The second assessment is an argumentative essay, evaluating both writing and analytical skill. The third assessment, a group project, usually focuses on a spoken element of rhetoric, evaluating the student's analytical and verbal skills. By virtue of its group nature, this last assessment also evaluates peer collaboration and negotiation.

These assessments, however, are designed with a "typical" student in mind and do not always consider SWDs (Abayasekara, 2020). In this instance, Mala (a pseudonym) who has a hearing impairment (HI) registered for the course. While she was keen and engaged in the classroom, at times she had difficulty in grasping class discussions and articulating her words clearly (Abayasekara, 2020). There were times I myself struggled as a teacher, not knowing the best method to deliver the course content. I realized that assessment number 3 would require some revision, as evaluating rhetorical skills pertaining to speech would be unfair by a SWD with hearing and speech difficulties. I also, however, did not want to give her a different assessment. While such a step would have abided by the principles of EAA, it would have been counterproductive to the group nature of the project and the required element of teamwork. Moreover, I did not want to differentiate between Mala and her peers, further polarizing those identifying as having a disability and not.

Taking these factors into account, I modified the requirements of the assessment. Instead of asking students to persuasively argue through a debate or panel discussion, I decided to test their skills of persuasive "production" through designing an advertisement (Abayasekara, 2020). The assessment would, then, not necessarily test verbal skills, but assess elements such as product choice and creative strategies of catering to the target audience. As noted in Abayasekara (2020), one may argue that even with this assessment, a student's familiarity with audio components would be necessary and that Mala would still be disadvantaged. However, Mala had shown engagement with audio elements in assessment 1 , and since this was a group project, she could leave the sounds component to be handled by her peers if she so wished. Moreover, colleagues who had taught her previously stated her keenness to engage in the same tasks as her peers, all of which added to the suitability of this assessment for the course. The class $(n=6)$ formed two groups, with three students per group.

As elaborated by me before (Abayasekara, 2020), the group assessment was very successful, with all students taking part enthusiastically. The group with Mala even included hearing impairment as part of the advertisement, highlighting how the selected product could cater to the HI population as they advertised Fitbit had a vibrator option for the HI. Thus, the assessment was not only inclusive in the skills tested but also increased awareness of disability-inclusive features and products. Moreover, whereas with the first assessment - the LMS post - Mala wrote on HI individually, with the group project, references to HI became a choice the entire group embraced.

Student performance also pointed to the success of the assessment, with both groups receiving high marks from the two examiners. Thus, in comparison to their grades for the other assessments for the course, the LMS posts and the argumentative essay, their 
performance at this particular assessment showed considerable improvement. Whereas the relatively strong students in the class had performed well on the other assessments, in this case all students performed well, indeed exceptionally so. One may argue that this was enabled by the group nature of the project, where, moreover, one grade is given to all students within the group. However, even within the group, an individual mark was given for each student's contribution and here too, all students scored a high mark.

Student feedback further indicated that the assessment had been an enjoyable educational exercise (Abayasekara, 2020). One student said it was a "rare opportunity" she did not think she would have again, while others referred to the opportunity it provided for them to be "creative in a different way" and to "think outside the box". All students stated that the assessment had facilitated the broadening of their knowledge by requiring them to apply their theoretical learning in the course to practical situations, a key purpose of assessment (Abayasekara, 2020). Such responses highlight the fact that the assessment benefitted all students and not just the student with HI, a key idea in UD.

Of the assessment, Mala noted, "This assessment gave us the opportunity to form close bonds with our team members. As group (sic) we had to make several plans and come up with n (sic) unique product to advertise" (Abayasekara, 2020, p. 9). Her statement indicates that an aim of the assessment, which was avoiding differentiating between students and building teamwork, had been met. Notably, Mala was the only student to explicitly comment on this aspect of bonding (Abayasekara, 2020). While another student in her group stated that she had learnt many things including how to carry out the activity respecting each other's boundaries and limits, and yet another student in the other group emphasized the level of teamwork required for this project unlike for other assessments, forming of inter-group ties was unique to Mala, indicating that the group aspect of the assessment carried special meaning for her (Abayasekara, 2020). Indeed, Hanafin et al. (2007) posit that "the competitive individualism intrinsic to an assessment structure can be invoked as a way of excluding disabled students and as an anti-learning mechanism" (p. 440). This observation lends credence to continuing with the same group project for all.

Mala's response to a question on the challenges the group faced in creating and producing the advertisement and how they were overcome is also significant. She stated:

We also had to think about showcasing the highlight of the product since this product was not well known in Sri Lanka and the smooth transition (sic). We figured we would start with the outstanding feature and then go on to the least important, but it plays a part on (sic) why all people can wear it [emphasis added].

This answer indicates the conscious decision that was made by the group to market a product that was universal in design and use that feature in the product's promotion, though they may not have been aware of the specific term UD.

Building on these reflections, I undertook a case study of Mala's perspectives on the assessment process both in relation to Rhetoric and Style and more generally. My methodology was a semi-structured interview with Mala, combined with elements of autoethnography. Key research questions were: 
a) What are Mala's views on assessment, primarily university assessment?

b) What are Mala's views on the assessments for the course Rhetoric and Style?

c) What might her responses indicate about her approach to learning?

d) What can I, as an educator, learn about inclusive assessment through her responses?

\section{The Case Study and Autoethnography}

Case study research is considered a valid form of inquiry to explore a range of complex issues, particularly when human behavior and social interactions are central to the topic/s under study (Harrison et al., 2017). Related to this aspect of interaction, case study is, as defined in the Merriam Webster Dictionary (n.d.), "an intensive analysis of an individual unit (as a person or community) stressing developmental factors in relation to environment". As Harrison et al. (2017) note, the fundamental goal of case study research is to conduct an in-depth analysis of an issue, within its context, in order to understand the issue from the perspective of the participants.

Linking case study to education, Harrison et al. (2017) write that, in the 1970's, educational research embraced case study as a way to assess curriculum design and innovation. Methods were required that could be used to explore aspects such as participants' perspectives and the influence of socio-political contexts on the curriculum's effectiveness. The authors noted that in the United Kingdom and United States, the development of case study research in education focused on the impact of educational programs and evidence for policy and practice supporting social and educational change.

These objectives illustrate the suitability of the case study approach to discuss inclusive assessment. A case study would provide an in-depth view of Mala's perspective on the assessments for the course Rhetoric and Style and educational assessment in general. It would also facilitate an understanding of the student's position in relation to her environment - be it in terms of course content, teaching learning activities (TLAs), lecturers, or peers - which, as highlighted before, are central in disability education. While the findings of my inquiry would not be applicable to all educational contexts involving SWDs, it would provide insights into the everyday experiences of a possibly highly marginalized individual, with little opportunity to express day-to-day experiences (Punch, 2005, as cited in Perera et al., 2020). It may also provide, as Harrison et al. (2017) state in relation to the United Kingdom and United States, points for reconsideration in education policies and practices.

This case study approach was complemented by the autoethnographic nature of the study, arising from my own reflections on inclusive assessment. Ellis et al. (2011) define autoethnography as "an approach to research and writing that seeks to describe and systematically analyze personal experience in order to understand cultural experience" (abstract). It is hoped, therefore, that my reflections would create a window to a larger exploration of how disability is navigated in specific educational contexts, and the types of accommodations that may be available for SWDs. Indeed, Ellis et al. (2011) emphasize that generalizability is important to autoethnographers, though not in the traditional positivist sense based on large random samples of respondents. In autoethnography, the focus of 
generalizability shifts from respondents to readers, as readers (in this case educators and perhaps students) constantly test whether a narrated experience speaks to them or not (Ellis, 2011).

As Ellis et al. (2011) also note, autoethnography recognizes and accommodates subjectivity, emotionality, and the researcher's influence on the research product. May and Perry (2014) also comment that in Max Weber's view (1949), "we cannot know the social world, but only our representations of that world. As researchers, there is no view we can derive that is free from social position given our participation in the social world" (p. 110). Therefore, researcher reflexivity becomes important, which as May and Perry observe, aid interpretation, translation, and representation. This fact is important to keep in mind when considering Mala's responses and my reflections on the same. Since I ask Mala primarily about a course I taught, her responses may well be shaped by her consciousness of me as the lecturer in charge of this course. In other words, even if the assessment were not very successful in her eyes, she may have been hesitant to say so. This limitation is mitigated by the in-depth interview in which she is not hesitant to mention problems with course delivery and assessment. The power dynamics between us also changed because during the period of the interview, I was no longer her teacher.

\section{Results and Discussion}

\section{Assessment in General and Approach to Learning}

I first asked Mala about her learning experiences at school. She stated that, overall, it was a greatly distressing one, with insufficient time and explanation of key concepts by the teachers. She noted that one teacher in Grade 7 had been very encouraging and had given her one-on-one time to help her grasp new concepts but that, overall, the teachers had not cared about her disability. She added that this may have been the case because teachers are required to teach large classes.

In terms of assessments in school, Mala stated that most of the tasks were written ones, and even in the rare instances where they were related to speech, she was given the option of a written assessment. Interestingly however, when asked how assessments in school could have been improved, Mala responded that the school curriculum could have focused on different types of assessments such as presentations and speeches, rather than simply written ones. This indicates a certain determination on Mala's part, to overcome barriers posed by hearing or speech impairment. It also signals her approach of considering how the learning process works for all students as opposed to just herself; she seems to indicate that different types of assessments would have benefitted not just her but her peers as well.

Mala made a similar statement in terms of determination when asked about assessment at university. She stated that written assessments were relatively easy for her to handle, while presentations were stressful as they required her to "learn how to speak... how to pronounce words"; but she also noted having found such presentations enjoyable. Despite Mala's opinion that written assessments were relatively less challenging than the 
spoken, her comments on the writing activities in the courses I taught signal challenges in writing tasks as well. In response to my question on how assessments at university could be/ could have been improved, Mala spoke about the mandatory academic writing course for first-year students of her department that I co-taught. She noted that the course had induced considerable stress as she was still getting accustomed to her new surroundings and to living away from home which was far from her university. She stated that she found academic writing difficult and wished it could have been introduced in Grade 10 or so, or taught at university over two years instead of one semester. This would have given her ample time to practice. Thus, any assumption that a student with hearing impairment requires, perhaps, additional support in terms of speech genres but not in reading and writing, is questionable. Mala's weaker performance in academic writing tasks corroborate this observation.

The danger of making such assumptions regarding assessment type, or any other factor relating to SWDs, highlights the need for student consultation. Dolmage (2017) emphasizes the necessity for consultation as UD has become "a way to talk about changing space to accommodate the broadest range of users, yet it consistently overlooks the importance of continued feedback from these users...[who] must be actively involved in the continued redesign of products, interfaces, and spaces" (p. 126). This does not mean the educator is obliged to always accommodate student preferences, and indeed, one would need to be judicious in incorporating student feedback, keeping in mind factors such as course and degree learning outcomes. But such a consultative process would make educators more aware of student needs than otherwise. Furthermore, it would give students, including those with disabilities, agency over and ownership of learning, thereby possibly increasing their motivation to learn.

I asked Mala if, as a class, students had been consulted at any point on the type of assessment they would like to have for a particular course. Initially, she did not directly answer the question; instead, she stated that some lecturers gave the freedom for students to decide if an assignment should be done individually or in groups and, if it was the latter option, allowed students to form their own groups. When I asked her how having this freedom felt, she commented, "It felt good. It felt easy. I did not have to go through the stress of having to manage with new group members." While this remark may be applicable to any student's feelings regarding groupwork, it is particularly understandable in the light of Mala's impairment, as forming peer connections through speech may be challenging. Mala added subsequently that in some courses, students suddenly receive a group task to be completed during class time, in randomly formed groups, which is graded. She described such activities as being very stressful as she would have to understand what each student was saying at a given point but could not keep asking "what-what-what?". The environment was not conducive to her active participation in the group task.

Mala thus immediately interprets the question above, about consultation regarding assignment type, as being about groupwork and group members. This reinforces the fact, highlighted in my previous discussion on the revised assessment for Rhetoric and Style, that she considered group bonds especially meaningful. When asked again about choice in assessment type, the student said that though they had not been consulted on the type, they 
did have flexibility at times regarding the topic and which type of assessment (e.g., written versus oral) they did first. For her then, concern about fellow group members seems to be as important as concern about assessment type noted before.

\section{Rhetoric and Style: Learning and Assessment}

Regarding the particular course Rhetoric and Style, Mala noted that she found it very interesting as she had to view material in a new way, but that she also found it stressful. When asked why that was so, she explained that with any course when the material is new, she felt stress springing from her childhood fear of encountering new concepts she could not understand. I then asked her how the content and TLAs of the course could have been improved to smoothen the process. She commented that if I had introduced the reading as one package before the start of the course, students would have had time to read during the vacation which would have been helpful. She added that when students are required to look at new material critically in class it makes them nervous. She also stated that with regard to assessment in Rhetoric and Style, her main challenge was writing the argumentative essay which had caused confusion amongst the class. She noted that a slower-paced assignment, with time to practice beforehand and more explanatory reading material would have been helpful. This response reinforces the cruciality of sufficient time for learning. Mala remarked in a jocular manner, that "there is a time crunch for everything!"

More importantly, however, Mala's response highlights her tendency to view a question through the lens of the entire class and not just her own. Except when describing her preference for choosing her own group members over being placed in a group, her answers constantly emphasized her consideration for the whole class. Even when asked about the challenges faced in the process of creating the advertisement for Rhetoric and Style, Mala described the issues encountered by the entire group, such as unfamiliarity with video editing and difficulties in finding a suitable environment for filming. Only when I specifically asked whether she faced any difficulties due to her impairment did she mention that it was not the case as the task was to do with a camera, which was another reason why she enjoyed the project. This inclusive approach possibly indicates her desire to consider a particular problem as applicable to all students and not just to her as a student with a hearing impairment. This also signals her desire, at least in certain instances, to be considered a regular student whose problems are not very different from those without hearing impairment and corroborates my colleagues' observations of Mala's preference for the same tasks as her peers.

The above relates to universal design for learning (UDL) in assessment. While there would be situations where assessment cannot accommodate all learning needs and EAA would have to be made, using the same assessment for all students whenever possible would, as indicated in the human rights approach to disability, promote a sense of belonging in SWDs. Lawson and Beckett (2020) note that while the solidarity generated by the social model creates a sense of collective belonging amongst people with different types of impairment, the cohesion generated by the human rights model, which is mainly between people with disabilities and others, creates a sense of belonging to the human race as a whole. 
Mala noted further that her group had students with different personalities, some dominant and others submissive. One student had been very shy to act, so Mala and the other group member had had to persuade her to do so. Mala's response indicates that she views herself as one of the dominant members of her group. As the students were encouraged to choose their own group members, Mala was, perhaps, comfortable in the group. This level of comfort may also have been aided by the small size of the class in which all the students knew each other and were sensitive to each other's needs. Thus, whereas in other contexts Mala might have been hesitant to speak out, here she found a voice.

Related to the aspect of finding a voice is Mala's reference to her idea of incorporating deafness into the advertisement, pointing to her innovativeness. She notes: "I was kind of having a deafness so we were like we could incorporate the deafness into the advertisement. So, it was kind of nice to see each one of us bring our strengths and everything". She had not seen a Fitbit with a vibrating feature before, but as vibration is a useful guide to the hearing impaired, she had suggested this feature be included in the advertisement. In fact, the suggestion to advertise a Fitbit in the first place, had also been hers. She clearly saw (and sees) deafness as a strength rather than a weakness and difference was not detrimental.

Engaging in the same tasks as her peers, which may also have increased Mala's motivation as a learner, helped prevent, in this instance, what a disability practitioner attached to a state university once termed a "special needs mentality". This is where some SWDs do not feel inspired to work hard for a degree due to their longstanding categorization, institutional and otherwise, as those with limited ability. Mala also reported that she took this opportunity to increase awareness of her impairment. She noted that in Sri Lanka, not many people know about deafness and believe it to be a sin of the parents - a view akin to the religious model of disability where it is seen as punishment for wrongdoing or one's karma (Gunawardena, 2020). Therefore, she wanted to "bring it forwards" for people to better understand her condition. She noted that her group peers had been very open to the idea of incorporating deafness into the advertisement but had not known how to implement it, whereupon she had demonstrated a method to do so.

This process indicates how a common assessment strategy could, facilitating solidarities, contribute to integration and encourage what Norbert Elias, in his personal pronoun model, terms the "we perspective"2 (as cited in Bessant, 2012). Katz (2013) reinforces the importance of such an integrated approach within UDL in describing what she terms the "three-block model of UDL", which provides educators with a method of creating inclusive learning environments and increasing student engagement. She recommends interactive tasks as opposed to parallel tasks and writes that "in the Three-Block Model of UDL ALL students work together", as it develops sensitivity to differing points of view, in turn encouraging critical thought (p. 166).

\section{Educator Awareness and Training}

Regardless of whether SWDs receive universally designed assessment or not, educator awareness, sensitization, and training are vital. This was highlighted by Mala in her statement that most teachers in her school did not seem to care about her disability, and 
that at university, impromptu groupings and pace had caused stress (see also Hettiarachchi et al., 2016). As Bessant (2012) suggests, without adequate awareness and training, a lecturer may well see a disability as "illegitimate" simply because s/he has not encountered it before, or because s/he may not know the procedures to follow on encountering a disability. Bessant adds that deficient awareness could lead to prejudice towards the student, which when communicated, could severely harm the student's self-confidence. Furthermore, such prejudice could both spring from and result in stigma (Dolmage, 2017). At the same time, Bessant points to the importance, in the case of an alternative assessment for a particular student, of knowing "how to make accommodations in assessment that do not embed a bias". Bessant also emphasizes the importance of giving "a realistic account of the student's learning" in any type of adjusted assessment (2012, p. 277). Therefore, as also indicated in Yatigammana et al. (2021), sufficient education on disability for staff, and ideally also for fellow students, is necessary to prevent SWDs from having to carry what Bessant terms the "burden of justice" (p. 278). In this instance this would be the responsibility for ensuring equitable evaluation.

Changed attitudes, therefore, are a must. Describing a case study where an assessment was revised over several months, Bessant (2012) notes that "as this change in perspective took place so too [did the staff's] capacity to identify their obligations enabling them to better grasp the need for alternative forms of assessment" (p. 272). Whether it be the same assessment given to all students, ensuring its suitability regardless of dis/ability, or an EAA, a change in perception, and thereby attitude, becomes key. This may then lead to policy changes as well.

\section{Conclusion: Now and Onward}

This article reflected on inclusive assessment practices for SWDs. It explored various models of disability, definitions of disability and the concepts of universal design (UD) and universal design in learning (UDL). It focused primarily on an approach within UDL of assessment that considers students both identifying as with, and without, disabilities. In doing so it examined, through a case study approach combined with elements of autoethnography, a specific change implemented in a course followed by a student with hearing impairment (HI). As Bessant (2012) notes, "insiders' accounts of how the problems are variously framed provides (sic) insights that can inform the kind of action that is needed if we are serious about inclusive education in the university" (pp. 279-280). A next step would be, therefore, to explore in detail how inclusivity can occur in overall course content and delivery, which is a much wider area than assessment only, and therefore one that requires far more deliberation and adjustment.

The "task of changing mindsets and deeply ingrained ideas" (Bessant, 2012, p. 279) is not easy and one that requires considerable time and effort. Yet doing so would serve SWDs, because the daily challenges they face in education, especially in the vital area of evaluation, would be acknowledged and addressed. Attitudinal change would, moreover, serve the entire academic community by making all stakeholders see the need for respectful accommodation. This would lead to a teaching and learning experience that is more participatory, diverse, and universal for all. 


\section{Acknowledgements}

This research was supported by the Accelerating Higher Education Expansion and Development (AHEAD) Operation of the Ministry of Higher Education funded by the World Bank. A special thank you to the editors and reviewers for their valuable feedback, to Prof. Dushyanthi Mendis for her suggestions and encouragement regarding the article, and to Mala, for very willingly sharing her thoughts with me.

1. Informed consent has been obtained from Mala and her group to use their evaluations for this article.

2. Bessant (2012) highlights the "perspectival nature" of education through this model. She notes that the model identifies who "I", "we" and "they" are in the educational context, and accordingly identifies the varying viewpoints of the stakeholders, which demonstrate how these stakeholders are represented and situated during negotiations.

\section{References}

Abayasekara, S. A. (2020). Inclusive assessment: Designing assessment according to student needs and abilities. 16th annual conference, Sri Lanka Association for Improving Higher Education Effectiveness (SLAIHEE), pp. 6-10.

https://www.researchgate.net/publication/343229923_Assessment_and_feedback-driven_ learning_platform_to_improve_the_attendance_of_undergraduates_in_tutorial_labsessions

Berghs, M., Chataika, T., El-Lahib, Y., \& Dube, K. (2019). The Routledge Handbook of Disability Activism. Routledge. https://doi.org/10.4324/9781351165082

Bessant, J. (2012). 'Measuring up'? Assessment and students with disabilities in the modern university. International Journal of Inclusive Education, 16(3), 265-281.

https://doi.org/10.1080/13603116.2010.489119

Biggs, J., \& Tang, C. (2007). Teaching for quality learning at university (3rd ed). Open University Press.

Brown, S., \& Smith, B. M. (1997). Getting to grips with assessment. Staff and Educational Development Association (SEDA).

Dolmage, J. T. (2017). Academic ableism: Disability and higher education. University of Michigan Press.

https://www.jstor.org/stable/j.ctvr33d50.7?refreqid=excelsior\%3A10dc718483fb4e04dc192734 dd76f4e8\&seq=1\#metadata_info_tab_contents

Ellis, C., Adams, T. E., \& Bochner, A. P. (2011). Autoethnography: An overview. Forum Qualitative Sozialforschung / Forum: Qualitative Social Research, 12(1), Article No. 10. https://doi.org/10.17169/fqs-12.1.1589

Gibbs, G., \& Habeshaw, T. (2011). Preparing to teach: An introduction to effective teaching in higher education. Technical \& Educational Services. (Original work published 1989) 
Gunawardena, N. (2020). Disability - Fact or myth? [PowerPoint slides]. Staff Development Centre and Centre for Disability Research, Education and Practice, University of Colombo.

Hanafin, J., Shevlin, M., Kenny, M., \& Mc Neela, E. (2007). Including young people with disabilities: Assessment challenges in higher education. Higher Education, 54(3), 435-448. DOI: 10.1007/ s10734-006-9005-9

Harrison, H., Birks, M., Franklin, R., \& Mills, J. (2017, January). Case study research: Foundations and methodological orientations. In Forum Qualitative Sozialforschung/Forum: Qualitative Social Research, 18(1), Article 19. https://doi.org/10.17169/fqs-18.1.2655

Hettiarachchi, S., Daskon-Attanayake, L., Ranaweera, M., \& Walisundara, D. (2016). Accessing tertiary education: Expectations and realities for students experiencing disabilities.

https://www.researchgate.net/publication/291447921_Accessing_tertiary_education_ expectations_and_realities_for_students_experiencing_disabilities

Johnson, R. L. (2011). Introduction: Health and disability. Health and History, 13(2), 2-12. https://doi.org/10.5401/healthhist.13.2.0002

Katz, J. (2013). The three-block model of universal design for learning (UDL): Engaging students in inclusive education. Canadian Journal of Education, 36(1), 153-194.

https://www.researchgate.net/publication/286055447_The_Three-Block_model_of_universal_ design_for_learning_UDL_Engaging_students_in_inclusive_education

Lawson, A., \& Beckett, A. E. (2020). The social and human rights models of disability: Towards a complementarity thesis. The International Journal of Human Rights, 25(2), 348-379.

https://doi.org/10.1080/13642987.2020.1783533

May, T., \& Perry, B. (2014). Reflexivity and the practice of qualitative research. In U. Flick (Ed.), The SAGE handbook of qualitative data analysis (Vol. 109, pp. 109-122). Sage. https://dx.doi.org/10.4135/9781446282243

Mendis, P., \& Perera, B. (2019). Disability policy brief for law makers, administrators, and other decision makers. International Centre for Ethnic Studies.

http://ices.lk/publications/disability-policy-brief-for-law-makers-administrators-and-otherdecision-makers/

Merriam-Webster. (n.d.). Case study. In Merriam-Webster.com dictionary. Retrieved May 21, 2021, from https://www.merriam-webster.com/dictionary/case $\% 20$ study

Ministry of Social Welfare. (2003). National policy on disability for Sri Lanka. http://67.199.83.28/doc/NatPolicyDisabilitySep2003srilanka1.pdf

Peiris-John, R. L., Attanayake, S., Daskon, L., Wickremasinghe, A. R., \& Ameratunga, S. (2013). Disability studies in Sri Lanka: Priorities for action. Disability and Rehabilitation, 36(20), 1742 1748. https://doi.org/10.3109/09638288.2013.864714

Perera, B., Kandasamy, N., \& Soldatic, K. (2020). Disability exclusion during the Coronavirus pandemic (COVID-19) in Sri Lanka. University of Colombo Review (Series III), 1(1), 47-59. https://hdl.handle.net/1959.7/uws:58200 
RMIT University. (n.d.). Equitable assessment arrangement.

https://www.rmit.edu.au/students/student-essentials/assessment-and-results/equitableassessment-arrangements

Samararatne, D. W., \& Soldatic, K. (2015). Inclusions and exclusions in law: Experiences of women with disability in rural and war-affected areas in Sri Lanka. Disability \& Society, 30(5), 759-772. https://doi.org/10.1080/09687599.2015.1021760

United Nations convention on the rights of persons with disabilities and optional protocol, December 13, 2006. https://www.un.org/disabilities/documents/convention/convoptprot-e.pdf

The World Bank. (2021, March 19). Disability inclusion.

https://www.worldbank.org/en/topic/disability

Yatigammana, S., Dorabawila, S., \& Abhayaratne, A. (2021). Developing inclusive education for students with disabilities in Sri Lankan universities (IncEdu): Needs assessment survey report. University of Peradeniya. A draft of the report can be found at http://www.esn.ac.lk/incedu/docs/Survey\%20Report\%20\%20Developing\%20Inclusive \%20 Education.pdf 